\title{
Genetics of quality and agronomic traits in hard endosperm maize
}

\author{
R. C. ALONSO FERRO ${ }^{1}$, R. A. MALVAR ${ }^{2}$, P. REVILLA ${ }^{2 *}$, A. ORDÁS ${ }^{2}$, P. CASTRO ${ }^{1}$ \\ AND J. MORENO-GONZÁLEZ ${ }^{1}$ \\ ${ }^{1}$ Centro de Investigacións Agrarias de Mabegondo (CIAM), Xunta de Galicia, Apartado 10, \\ 15080 A Coruña, Spain \\ ${ }^{2}$ Misión Biológica de Galicia (CSIC), Apartado 28, 36080 Pontevedra, Spain
}

(Revised MS received 2 May 2008; First published online 22 July 2008)

\begin{abstract}
SUMMARY
Hard endosperm maize (Zea mays L.) is useful for industry and for human consumption. The objective of the present work was to study the inheritance of quality traits in hard endosperm maize. Three flint and three dent inbreds, $\mathrm{F}_{1}$ of their diallel crosses, $\mathrm{F}_{2} \mathrm{~s}$ and backcrosses to each parent were evaluated for grain yield and quality traits (flotation test, flour-milling test, grain damage (GD) index and grain density). Genotypes and genotype $\times$ environment interactions were significant for most traits. A genetic model including additive, dominance and epistatic effects explained most of the genetic variation for the traits. Additive effect mean squares were larger than those due to dominance effects, except for grain yield and GD. Partition of the dominance variance into average, general, and specific dominance components revealed that the average dominance related to heterosis was the most important. Additive $\times$ additive epistatic variation was smaller than additive and dominance variation for quality traits. Some inbreds displayed sufficient potential to be used in hard endosperm maize breeding programmes. The average dominance effect was favourable for most of the quality and agronomic traits. Breeding programmes for improving quality in hard endosperm maize would be most efficient if both additive and dominant effects are capitalized on.
\end{abstract}

\section{INTRODUCTION}

The importance of maize (Zea mays L.) and its products in the human diet is recognized by the Food and Agriculture Organization of the United Nations (FAO 1992). However, in the European Union less than one-tenth of the maize produced is destined for human consumption as maize flour, cornstarches, breakfast cereals and other products (EUROSTAT 2005).

Little research has been carried out so far on the characteristics of maize cultivars to be used as human food. Therefore, it is appropriate to determine this in order to develop new maize varieties destined for human consumption with higher added value. Maize grain quality and technological characteristics are important for maize food industries. The quality of the

* To whom all correspondence should be addressed. Email: previlla@mbg.cesga.es grain depends on the type of maize, the environmental growing conditions and the post-harvest management (Audilakshmi \& Aruna 2005). General aspects of quality and technology applied to maize for human diet have been described by Watson \& Ramstad (1987) and Matz (1991).

Generally, corn flakes are made from hard endosperm maize with flint crown, yellow-orange colour and uniform size, because hard grains are required for producing larger particle size after milling. The production process of corn flakes has been detailed by Fast (1990). This type of maize has been called Plata maize, with reference to the Argentinean region where it comes from. The quality of this type of maize has been widely studied (Robutti et al. 2000), but the genetics and breeding has been neglected. Particularly, no specific breeding programme for selecting hard-grain maize hybrids exists so far in Europe.

The grain hardness depends mainly on the relation between horny and floury endosperms and 
secondarily on the structure and compacting of cell components and thickness of the pericarp. The level of hardness is determined, in the cells of the endosperm, by the structure of the zeins and starches and by the bond between them (Chandrashekar \& Mazhar 1999). The hardness has shown a strong relationship with other quality traits, especially with grain density (Dorsey Redding et al. 1991).

The main objective of the present work was to study the inheritance of the grain quality traits in hard endosperm maize preparotary to the development of new varieties with improved grain quality and agronomic value for human consumption.

\section{MATERIALS AND METHODS}

\section{Genetic materials}

The plant material used in the present study included six maize inbreds. Three had flint endosperm: EP39 is an inbred line developed from the southern Spanish population Fino of Plata type; EC13A is a first-cycle inbred line developed from the local landrace Pontedeume, Corunna, Spain; EA2024 was released from the population Colorado Klein, related to the Argentinean type of Plata maize. Three had dent endosperm: CM105 is related to the Iowa Stiff Stalk Synthetic population (BSSS); B93 was developed from the backcross population of $(\mathrm{B} 70 \times \mathrm{H} 99) \times \mathrm{H} 99$ and so is related to Lancaster germplasm; EP29 was obtained from the Synthetic population AS-3(HT)C3 in the MBG, Pontevedra, Spain. Crosses among the inbreds were made in 1999, following a diallel mating system without reciprocal crosses. In 2000 , the $F_{2}$ and the backcross generations to each parent were obtained.

\section{Field evaluation}

The 66 genotypes derived from the six inbreds were classified into 15 groups, in such a way that each group included the related genotypes of the parental inbred combination $\mathrm{P}_{1}$ and $\mathrm{P}_{2}$ and their derived generations $F_{1}$ and $F_{2}$, and the two backcrosses $\left(\mathrm{BC}_{1}\right.$ and $\mathrm{BC}_{2}$ ). All the genotypes were grown at two locations in Spain during 2001 : Pontevedra $\left(42^{\circ} 24^{\prime} \mathrm{N}\right.$, $8^{\circ} 38^{\prime} \mathrm{W}$ and $20 \mathrm{~m}$ asl) and Abegondo $\left(43^{\circ} 14^{\prime} \mathrm{N}\right.$, $8^{\circ} 15^{\prime} \mathrm{W}$ and $97 \mathrm{~m}$ asl). The experiment was laid out as a split-plot design, with the groups assigned to all the plots and generations within each group to the subplots. Depending upon the heterogeneity of the segregating material, the subplots comprised different numbers of 40-plant rows viz. one row for the $F_{1}$, two for the inbreds, and five each for the $\mathrm{F}_{2}, \mathrm{BC}_{1}$ and $\mathrm{BC}_{2}$. Distance between the plants was $0.2 \mathrm{~m}$ and between the rows was $0.8 \mathrm{~m}$, giving a final density of 60000 plants/ha. Five randomly selected plants from each row were self-pollinated and used for ear determinations. Two and three replications were available from the Corunna and Pontevedra trials, respectively.

Data were recorded for agronomic traits including anthesis and silking dates (days) and grain yield (t/ha) adjusted to moisture content of $155 \mathrm{~g} / \mathrm{kg}$. The selfpollinated ears were harvested and shelled and a representative sample of grain from each plot was saved. Data for grain weight and the flotation test (FT) were recorded at the Centro de Investigacións Agrarias de Mabegondo using the grain samples obtained in Mabegondo, whereas grain damage (GD), density and flour-milling test (FMT) were analysed at the Misión Biológica de Galicia (CSIC).

The FMT measures the proportion of flour passing through a sieve of $1 \mathrm{~mm}$ diameter netting after milling $50 \mathrm{~g}$ of grain samples with a grinder for a given time (15 s). A 1000-grain sample of the harvested grain was used for obtaining the grain weight, expressed in $\mathrm{mg}$. True density was measured in a test tube as the ratio between $100 \mathrm{~g}$ of grain and the volume of ethanol displaced and converted into water displacement as a standard for specific gravity $\left(\mathrm{g} / \mathrm{cm}^{3}\right)$. The FT was determined by introducing 100 grains in a solution of sodium nitrate of density $1.25 \mathrm{~g} / \mathrm{cm}^{3}$. After shaking for $5 \mathrm{~min}$, floating and sunk grains were separated, dried and weighed. The flotation index was calculated as the proportion of floating grains in the whole sample.

Near infrared reflectance spectroscopy (NIRS) analysis of grain samples was carried out with a Perstop Analytical Nirsystem equipment. An equation was developed relating the flotation index to NIRS spectra. The equation estimated flotation indices that were obtained using the NIR ISI II software program (Infrasoft International, LLC, Silver Springs, Maryland, USA) for all the whole grain samples. The reflectance spectra were obtained $(\log 1 / R v . \lambda$, where $R$ is the reflectance and $\lambda$ is the wave length) for the $\lambda$ ranges $408-1092$ and $1108-2493 \mathrm{~nm}$. By using modified partial minimum squares, the calibration curves were developed for milling test, density and flotation. The equations were calibrated and validated with 116 and 45 samples, respectively, for flotation index and with 149 and 176 samples, respectively, for milling tests. The $R^{2}$ of calibration for FT and FMT were 0.82 and 0.68 , respectively, with standard errors of 12.3 and 4.33 , respectively; the $R^{2}$ for predictions were 0.87 and 0.77 with standard error of 10.7 and 3.39 for FT and FMT, respectively.

GD was estimated visually as follows: $50 \mathrm{~g}$ of whole grains were placed in a $1 \mathrm{~g} /$ litre volume solution of brilliant blue R-250 dye in distilled water for $30 \mathrm{~s}$, removed, washed with tap water for $30 \mathrm{~s}$, placed on paper towels and allowed to dry. The dye penetrates the grain fractures, while the undamaged grains lose all the blue colour when washed. Undamaged grains were then counted, following the method of 
Henry \& Kettlewell (1996). A weighted GD index was calculated as follows:

$$
\mathrm{GD}=(4 s+2 l+w)
$$

where $s$ is the proportion of grains with severe damage, $l$ is the proportion of grains with light damage and $w$ is the proportion of grains without damage.

\section{Genetic model}

A modification of Moreno-González \& Dudley's model (1981) was adopted for analysing the genetic information. This modification involved a change for overcoming the confounding effects of the MorenoGonzález \& Dudley (1981) model for additive $\times$ additive epistasis, additive effects and overall mean, so that additive $\times$ additive epistasis of each cross $\left(a a_{i j}\right)$ was subdivided as follows:

$$
a a_{i j}=a a_{i}+a a_{j}+2 a a_{i j}^{\prime}
$$

where $a a_{i}$ and $a a_{j}$ are components of general additive $\times$ additive epistasis for inbreds $i$ and $j$ respectively and $a a_{i j}^{\prime}$ is the specific additive $\times$ additive epistasis for segregating populations derived from crossing $i$ and $j$.

The additive $x$ dominance and dominance $x$ dominance epistasis of Moreno-González \& Dudley (1981) model were not considered in this model. The coefficients of additive $\times$ additive effects were in accordance with the scale used in the model proposed by Xu \& Zhu (1999).

The resulting model for the six generations $\left(\mathrm{P}_{1}, \mathrm{P}_{2}\right.$, $\mathrm{F}_{1}, \mathrm{~F}_{2}, \mathrm{BC}_{1}$ and $\mathrm{BC}_{2}$ ) derived from $i$ and $j$ parent lines can be written as follows:

$$
\begin{gathered}
\mathrm{P}_{1}: y_{i}=\mu+a_{i}+4 a a_{i} \\
\mathrm{P}_{2}: y_{j}=\mu+a_{j}+4 a a_{j} \\
\mathrm{~F}_{1}: y_{i j}=\mu+1 / 2 a_{i}+1 / 2 a_{j}+d_{i j}+a a_{i}+a a_{j}+2 a a_{i j}^{\prime} \\
\mathrm{F}_{2}: y_{i j}=\mu+1 / 2 a_{i}+1 / 2 a_{j}+1 / 2 d_{i j}+a a_{i}+a a_{j}+2 a a_{i j}^{\prime} \\
\mathrm{BC}_{1}: Y_{i j i}=\mu+3 / 4 a_{i}+1 / 4 a_{j}+1 / 2 d_{i j}+9 / 4 a a_{i} \\
+1 / 4 a a_{j}+3 / 2 a a_{i j}^{\prime} \\
\mathrm{BC}_{2}: Y_{i j j}=\mu+1 / 4 a_{i}+3 / 4 a_{j}+1 / 2 d_{i j}+1 / 4 a a_{i} \\
+9 / 4 a a_{j}+3 / 2 a a_{i j}^{\prime}
\end{gathered}
$$

where $y$ refers to phenotypic means; $\mu$ is the population mean; subscripts $i, j, i j, i j i$ and $i j j$ refer to parents $i$ and $j, \mathrm{~F} 1$ or $\mathrm{F} 2$ of the cross $i \times j$, and the backcrosses to parent $i$ and $j$, respectively; $a_{i}$ and $a_{j}$ are additive effects of parents $i$ and $j$, respectively; $d_{i j}$ is the dominance effect of the $i \times j$ cross; $a a_{i j}^{\prime}$ is specific additive $\times$ additive $(a a)$ epistasis of the $i \times j$ cross; and $a a_{i}$ and $a a_{j}$ are the general $a a$ epistasis of parents $i$ and $j$, respectively.

Restrictions of the model were:

$\Sigma a_{i}=0$, where $i=1, \ldots, n$ is the number of lines, and $\Sigma a a_{i j}^{\prime}=0$ for each $i$ and $j$.

Dominance effects were further partitioned in a similar way as Eberhart \& Gardner (1966) did for heterosis:

$$
d_{i j}=\bar{d}+d_{i}+d_{j}+s_{i j}
$$

where $d_{i j}$ is the dominance effect of the cross, $\bar{d}$ is the average dominance for the overall mean of $F_{1}$ crosses, $d_{i}$ and $d_{j}$ are the general dominance for the crosses involving line $i$ or $j$, respectively, and $d_{i j}$ is the specific dominance for $i \times j$ cross, with the following restrictions:

$$
\begin{gathered}
\Sigma d_{i j}=0, \Sigma s_{i j}=0 \text { for each } i \text { where } j=1, \ldots, n ; \\
\Sigma d_{i}=0 \text { and } \Sigma d_{j}=0
\end{gathered}
$$

An important consideration in the genetic model is that dominance is related to heterosis but they are not synonyms since heterosis is a function of dominance and epistatic effects:

$$
h_{i j}=F_{1}-1 / 2\left(P_{1}+P_{2}\right)=d_{i j}-a a_{i}-a a_{j}+a a_{i j}^{\prime}
$$

where $h_{i j}$ is the heterosis of the $i \times j$ cross relative to the mid-parent.

\section{Statistical analysis}

Several statistical analyses were performed with the SAS utilities (SAS Institute Inc 1999). A least squares analysis of variance (ANOVA) was carried out, taking genotype as fixed effect and environment and repetition as random effects. The analysis was carried out by sequential adjustment of data to sub-models, similar to Eberhart (1964) and Moreno-González \& Dudley (1981):

$$
\mu+a_{i}+a_{j}+\bar{d}
$$

Sum of squares $=\mathrm{S} 1$

(Model 1)

$$
\mu+a_{i}+a_{j}+\bar{d}+d_{i}+d_{j}+s_{i j}
$$

Sum of squares $=\mathrm{S} 2$

(Model 2)

$$
\mu+a_{i}+a_{j}+\bar{d}+d_{i}+d_{j}+s_{i j}+a a_{i}+a a_{j}+a a_{i j}^{\prime}
$$

Sum of squares $=\mathrm{S} 3$

(Model 3)

Genetic effects in the genetic model were estimated by using the mixed linear model (MLM):

$$
\mathbf{y}_{i j}=\mathbf{X} \boldsymbol{\beta}+\mathbf{Z} \boldsymbol{\gamma}+\boldsymbol{\varepsilon}
$$


Table 1. Predicted additive, dominance and epistatic effects for grain yield based on the three models for Abegondo and Pontevedra (Spain) in 2001

Estimated genetic effects

\begin{tabular}{|c|c|c|c|c|c|c|c|c|c|c|c|c|}
\hline \multirow[b]{2}{*}{$\begin{array}{l}\text { Parental } \\
\text { genotype }\end{array}$} & \multicolumn{2}{|c|}{ Model I* } & \multicolumn{4}{|c|}{ Model II $\dagger$} & \multicolumn{6}{|c|}{ Model III* } \\
\hline & \multicolumn{2}{|c|}{ Additive } & \multicolumn{2}{|c|}{ Additive } & \multicolumn{2}{|c|}{$\begin{array}{c}\text { General } \\
\text { dominance }\end{array}$} & \multicolumn{2}{|c|}{ Additive } & \multicolumn{2}{|c|}{$\begin{array}{c}\text { General } \\
\text { dominance }\end{array}$} & \multicolumn{2}{|c|}{$\begin{array}{c}\text { General } \\
\mathrm{A} \times \mathrm{A} \text { epistasis }\end{array}$} \\
\hline & & $P$ & & $P$ & Grain & yield $(\mathrm{t} /$ & & $P$ & & $P$ & & $P$ \\
\hline B93 & 1.80 & $<0.01$ & 0.76 & $<0.05$ & 1.90 & $<0 \cdot 01$ & 0.74 & $<0.05$ & 1.90 & $<0.01$ & $0 \cdot 00$ & NS \\
\hline CM105 & $-0 \cdot 18$ & NS & $-0 \cdot 61$ & NS & 0.81 & NS & $-0 \cdot 60$ & NS & 0.82 & NS & $-0 \cdot 01$ & NS \\
\hline EA2024 & $-0 \cdot 40$ & NS & $0 \cdot 14$ & NS & $-0 \cdot 96$ & NS & $0 \cdot 14$ & NS & $-0 \cdot 95$ & NS & $0 \cdot 00$ & NS \\
\hline EC13A & $-0 \cdot 15$ & NS & $0 \cdot 29$ & NS & -0.91 & NS & $0 \cdot 29$ & NS & -0.89 & NS & $0 \cdot 00$ & NS \\
\hline EP29 & $0 \cdot 54$ & NS & 0.03 & NS & $0 \cdot 80$ & NS & $0 \cdot 02$ & NS & $0 \cdot 77$ & NS & $0 \cdot 00$ & NS \\
\hline EP39 & $-1 \cdot 60$ & $<0.01$ & $-0 \cdot 61$ & NS & -1.60 & $<0.05$ & $-0 \cdot 60$ & NS & $-1 \cdot 60$ & $<0.05$ & $-0 \cdot 01$ & NS \\
\hline $\begin{array}{l}\text { Average } \\
\text { dominance }\end{array}$ & $6 \cdot 30$ & $<0 \cdot 01$ & NS & NS & $6 \cdot 40$ & $<0.01$ & NS & NS & $6 \cdot 30$ & $<0.01$ & NS & NS \\
\hline
\end{tabular}

* Model I average dominance was fixed and general additive effects were random.

$\dagger$ Model II average dominance was fixed and general additive and dominance effects were random.

\$ Model III average dominance was fixed, and general additive, dominance and epistatic effects were random.

NS, not significant.

where $\boldsymbol{y}_{i j}$ is a vector of observations of different generations, $\boldsymbol{\beta}$ the vector of fixed genetic effects, $\boldsymbol{\gamma}$ the vector of random effects, $\mathbf{X}$ the matrix that relates observations and fixed effects, $\mathbf{Z}$ the matrix that relates observations and random effects, and $\varepsilon$ is the vector of residual random effects (error).

Three MLM analyses I, II and III were sequentially performed. In analysis I, the average dominance was assumed fixed and general additive effects were random. In analysis II, the average dominance was considered fixed and general additive and dominance effects were random. In analysis III, the average dominance was considered fixed, while the general additive, dominance and epistatic effects were random. Average dominance was considered fixed because a unique effect, which was assumed different from zero, was estimated for this parameter. Finally, the Pearson correlation coefficients among quality and agronomic traits were estimated.

\section{RESULTS}

In the combined ANOVA, the environmental variations and the genotype $\times$ environment interaction were significant for three out of six traits, specifically for grain yield, FMT and GD. Therefore, these were used as error terms for testing the significance of genotypes for these traits. A significant part of the variation, about $0 \cdot 15$ of total sum of squares for grain yield, were explained by the interaction of the different response of genotypes to environments for these three traits. Genotypes were significantly different for all agronomic and quality traits except for GD and density.

The proposed genetic model was significant for all traits except for GD (data not shown). The model explained more than 0.7 of the total genotype sum of squares for quality traits and up to 0.93 for grain yield. The genetic effects differed for each trait as follows:

Grain yield: Mean squares due to dominance effects were several times larger than those due to additive and epistatic effects. A positive average dominance effect was the most important genetic effect controlling grain yield (Table 1). Positive significant additive and dominance effects were detected for inbred B93 and negative for inbred EP39. No significant epistatic effects for grain yield were detected when the two environments were considered, however, positive specific epistatic effects were found in seven out of 15 crosses in the Mabegondo environment (data not shown).

FMT: The mean squares of additive effects were the largest ones among the genetic effects for this trait. Variation of dominance effects was not significant when genotypes were tested in the two environments, probably due to the large genotype $x$ environment interaction. Specific dominance was detected, while the additive $\times$ additive epistatic variation was not significant for the FMT. A positive effect of average dominance was found for the FMT (Table 2). Furthermore, negative additive effects were observed for the Plata inbreds, EA2024 and EP39, and positive for the soft endosperm inbreds, B93 and EP29. 
Table 2. Predicted additive, dominance and epistatic effects for flour-milling test based on the three models for Abegondo and Pontevedra (Spain) in 2001

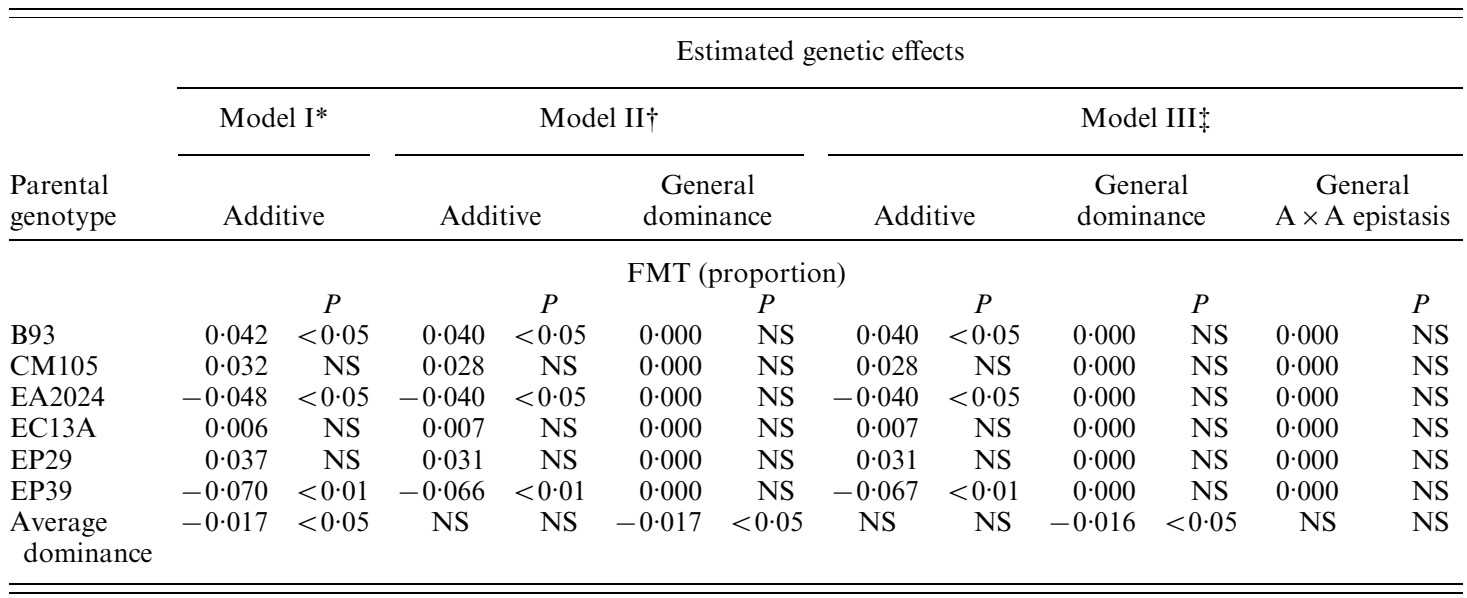

* Model I average dominance was fixed and general additive effects were random.

$\uparrow$ Model II average dominance was fixed and general additive and dominance effects were random.

\$ Model III average dominance was fixed, and general additive, dominance and epistatic effects were random.

NS, not significant.

Table 3. Predicted additive, dominance and epistatic effects for grain damage based on the three models for Abegondo and Pontevedra (Spain) in 2001

Estimated genetic effects

\begin{tabular}{|c|c|c|c|c|c|c|c|c|c|c|c|c|}
\hline \multirow[b]{2}{*}{$\begin{array}{l}\text { Parental } \\
\text { genotype }\end{array}$} & \multicolumn{2}{|c|}{ Model I* } & \multicolumn{4}{|c|}{ Model $\mathrm{II} \dagger$} & \multicolumn{6}{|c|}{ Model III } \\
\hline & \multicolumn{2}{|c|}{ Additive } & \multicolumn{2}{|c|}{ Additive } & \multicolumn{2}{|c|}{$\begin{array}{c}\text { General } \\
\text { dominance }\end{array}$} & \multicolumn{2}{|c|}{ Additive } & \multicolumn{2}{|c|}{$\begin{array}{c}\text { General } \\
\text { dominance }\end{array}$} & \multicolumn{2}{|c|}{$\begin{array}{c}\text { General } \\
\mathrm{A} \times \mathrm{A} \text { epistasis }\end{array}$} \\
\hline \multicolumn{13}{|c|}{ GD (index) } \\
\hline & & $P$ & & $P$ & & $P$ & & $P$ & & $P$ & & $P$ \\
\hline B93 & $4 \cdot 2$ & NS & $4 \cdot 3$ & NS & $1 \cdot 3$ & NS & $0 \cdot 0$ & NS & $0 \cdot 0$ & NS & $2 \cdot 3$ & $<0.05$ \\
\hline CM105 & $5 \cdot 0$ & NS & $8 \cdot 0$ & $<0.05$ & $-4 \cdot 5$ & NS & $0 \cdot 0$ & NS & $0 \cdot 0$ & NS & $3 \cdot 1$ & $<0.01$ \\
\hline EA2024 & $-1 \cdot 1$ & NS & $-0 \cdot 2$ & NS & $-2 \cdot 2$ & NS & $0 \cdot 0$ & NS & $0 \cdot 0$ & NS & $0 \cdot 9$ & NS \\
\hline EC13A & -0.5 & NS & $0 \cdot 2$ & NS & $-1 \cdot 5$ & NS & $0 \cdot 0$ & NS & $0 \cdot 0$ & NS & $1 \cdot 0$ & NS \\
\hline EP29 & $-6 \cdot 0$ & NS & $-8 \cdot 0$ & $<0 \cdot 05$ & $1 \cdot 9$ & NS & $0 \cdot 0$ & NS & $0 \cdot 0$ & NS & $-1 \cdot 7$ & NS \\
\hline EP39 & $-1 \cdot 6$ & NS & $-4 \cdot 3$ & NS & $4 \cdot 9$ & NS & $0 \cdot 0$ & NS & $0 \cdot 0$ & NS & $-1 \cdot 0$ & NS \\
\hline $\begin{array}{l}\text { Average } \\
\text { dominance }\end{array}$ & $-23 \cdot 0$ & $<0 \cdot 01$ & NS & NS & $-23 \cdot 0$ & $<0 \cdot 01$ & NS & NS & $-20 \cdot 0$ & $<0 \cdot 01$ & NS & NS \\
\hline
\end{tabular}

* Model I average dominance was fixed and general additive effects were random.

$\uparrow$ Model II average dominance was fixed and general additive and dominance effects were random.

\$ Model III average dominance was fixed, and general additive, dominance and epistatic effects were random.

NS, not significant.

GD index: Genotypic variation for GD was not significant in the combined analysis (Table 3 ). If the experimental error was used as denominator in $F$ tests instead of the genotype $\times$ environment interaction mean squares, the genotypic variation would be significant, thus the different responses of genotypes to environments cancel out the importance of genotype variation per se for this trait. Dominance mean square was significant. When the dominance source of variation was partitioned into components, the mean squares of average dominance related to average heterosis was very large, suggesting a highly 
Table 4. Predicted additive, dominance and epistatic effects for grain density based on the three models for Abegondo and Pontevedra (Spain) in 2001

Estimated genetic effects

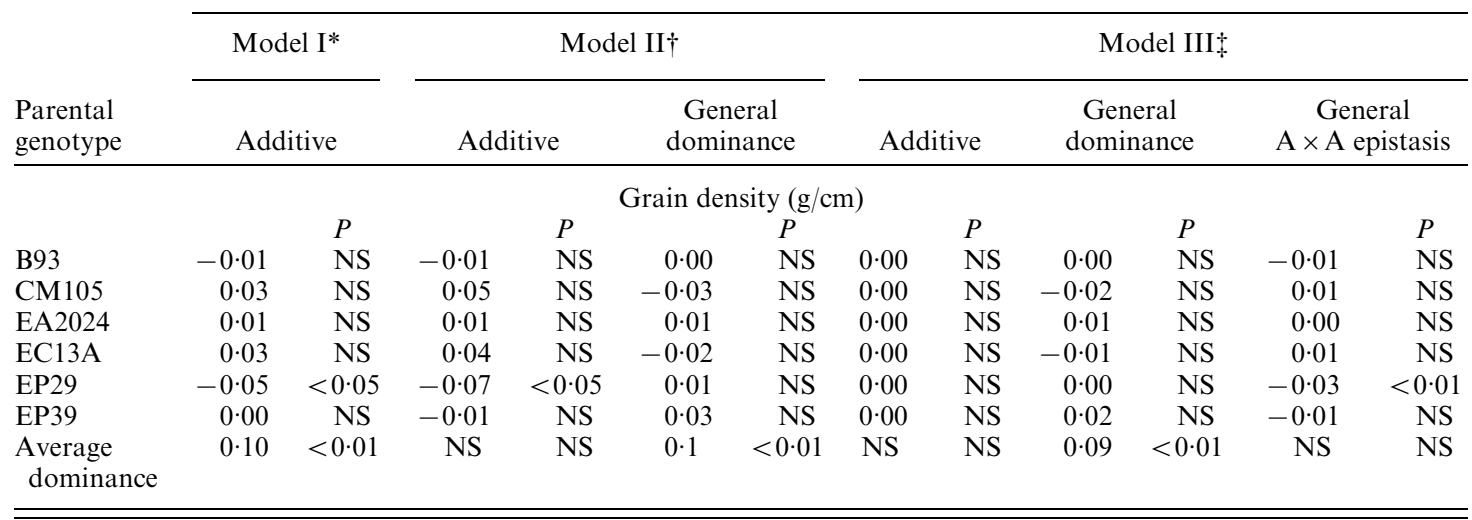

* Model I average dominance was fixed and general additive effects were random.

$\uparrow$ Model II average dominance was fixed and general additive and dominance effects were random.

\$ Model III average dominance was fixed, and general additive, dominance and epistatic effects were random.

NS, not significant.

significant difference between inbreds and crosses for resistance to GD. Additive mean square was smaller than that due to dominance effects for these traits. No significant epistatic variation was found for GD.

Considering that negative effects involve a reduction in GD, the most important genetic effect for GD was a negative average dominance, which indicates that hybrids are less susceptible to postharvest damage than inbreds. Additive effects were positive for inbred CM105 and negative for inbred EP29. However, positive additive $\times$ additive epistasis effect was detected for both inbreds B93 and CM105.

Grain density: The variation due to genotypes was not significant, however additive and dominance effects were significant, which indicates that these two types of effects are mainly governing the genetic behaviour of genotypes for grain density without significant influence of epistatic effects. The mean squares of additive effects were larger than those of dominance effects. When the dominance source of variation was partitioned into components, the average dominance component was found to be larger than any other, because hybrids had higher grain density compared with inbreds. Genotypes were not significantly different, although some of the genetic effects were significant for grain density.

Positive average dominance effects were detected for grain density. Significant negative additive and additive $\times$ additive effects were detected for inbred EP29 (Table 4).

FT: The mean squares due to additive effects were several times larger than those due to dominance effects, indicating that the additive effects were the most important in the genetics of this trait. Partitioning of dominance variance resulted in significant mean squares for their three components. The average dominance mean squares were several times larger than the other dominance components, showing that hybrids had lower flotation than inbreds. No significant additive $\times$ additive epistatic variation was found.

A negative effect of average dominance was found for FT (NIRS estimates), as hybrids showed better quality endosperm characteristics than inbreds for being used in the maize processing industry (Table 5). A positive additive effect was detected for the soft endosperm inbred EP29 and a negative effect for the inbred EA2024 related to Plata maize. Also, a positive epistatic additive $\times$ additive effect was detected for the EP29, which reveals an additional positive genetic effect for the industrial use of this inbred for endosperm quality. It has to be kept in mind that negative effects imply reduction of floatability, which means higher quality.

Grain weight: The additive mean squares of grain weight were larger than those of dominance and epistatic effects. Partitioning dominance variance into components, the average dominance was found to be the largest. Epistatic effects were significant but several times smaller than other effects. The signs of genetic effects of grain weight were similar to those of grain yield for inbreds which showed significant additive effect estimates in crosses with B93 and EP39 inbreds (Table 6). 
Table 5. Predicted additive, dominance and epistatic effects for flotation test based on the three models for Abegondo and Pontevedra (Spain) in 2001

Estimated genetic effects

\begin{tabular}{|c|c|c|c|c|c|c|c|c|c|c|c|c|}
\hline \multirow[b]{2}{*}{$\begin{array}{l}\text { Parental } \\
\text { genotype }\end{array}$} & \multicolumn{2}{|c|}{ Model I* } & \multicolumn{4}{|c|}{ Model II $\dagger$} & \multicolumn{6}{|c|}{ Model III } \\
\hline & \multicolumn{2}{|c|}{ Additive } & \multicolumn{2}{|c|}{ Additive } & \multicolumn{2}{|c|}{$\begin{array}{c}\text { General } \\
\text { dominance }\end{array}$} & \multicolumn{2}{|c|}{ Additive } & \multicolumn{2}{|c|}{$\begin{array}{c}\text { General } \\
\text { dominance }\end{array}$} & \multicolumn{2}{|c|}{$\begin{array}{c}\text { General } \\
\mathrm{A} \times \mathrm{A} \text { epistasis }\end{array}$} \\
\hline \multicolumn{13}{|c|}{ FT (NIRS prediction) (proportion) } \\
\hline & & $P$ & & $P$ & & $P$ & & $P$ & & $P$ & & $P$ \\
\hline B93 & $-0 \cdot 062$ & NS & $-0 \cdot 077$ & NS & $0 \cdot 026$ & NS & $0 \cdot 000$ & NS & $0 \cdot 017$ & NS & $-0 \cdot 015$ & NS \\
\hline CM105 & $0 \cdot 005$ & NS & $-0 \cdot 022$ & NS & $0 \cdot 047$ & NS & $0 \cdot 000$ & NS & $0 \cdot 055$ & NS & $-0 \cdot 002$ & NS \\
\hline EA2024 & $-0 \cdot 150$ & $<0.05$ & $-0 \cdot 130$ & $<0.05$ & $-0 \cdot 040$ & NS & $0 \cdot 000$ & NS & -0.079 & NS & -0.027 & NS \\
\hline EC13A & $0 \cdot 100$ & NS & 0.076 & NS & $0 \cdot 035$ & NS & 0.000 & NS & $0 \cdot 063$ & NS & $0 \cdot 024$ & NS \\
\hline EP29 & $0 \cdot 220$ & $<0.01$ & $0 \cdot 230$ & $<0.01$ & -0.007 & NS & $0 \cdot 000$ & NS & $0 \cdot 040$ & NS & 0.069 & $<0.01$ \\
\hline EP39 & $-0 \cdot 120$ & NS & $-0 \cdot 077$ & NS & $-0 \cdot 062$ & NS & $0 \cdot 000$ & NS & -0.096 & NS & $-0 \cdot 011$ & NS \\
\hline $\begin{array}{l}\text { Average } \\
\text { dominance }\end{array}$ & $-0 \cdot 160$ & $<0.01$ & NS & NS & $-0 \cdot 170$ & $<0.01$ & NS & NS & $-0 \cdot 154$ & $<0.01$ & NS & NS \\
\hline
\end{tabular}

* Model I average dominance was fixed and general additive effects were random.

$\uparrow$ Model II average dominance was fixed and general additive and dominance effects were random.

\$ Model III average dominance was fixed, and general additive, dominance and epistatic effects were random.

NS, not significant.

Table 6. Predicted additive, dominance and epistatic effects for grain weight based on the three models for Abegondo and Pontevedra (Spain) in 2001

Estimated genetic effects

\begin{tabular}{|c|c|c|c|c|c|c|c|c|c|c|c|c|}
\hline \multirow[b]{2}{*}{$\begin{array}{l}\text { Parental } \\
\text { genotype }\end{array}$} & \multicolumn{2}{|c|}{ Model I* } & \multicolumn{4}{|c|}{ Model II $\dagger$} & \multicolumn{6}{|c|}{ Model III } \\
\hline & \multicolumn{2}{|c|}{ Additive } & \multicolumn{2}{|c|}{ Additive } & \multicolumn{2}{|c|}{$\begin{array}{c}\text { General } \\
\text { dominance }\end{array}$} & \multicolumn{2}{|c|}{ Additive } & \multicolumn{2}{|c|}{$\begin{array}{c}\text { General } \\
\text { dominance }\end{array}$} & \multicolumn{2}{|c|}{$\begin{array}{c}\text { General } \\
\mathrm{A} \times \mathrm{A} \text { epistasis }\end{array}$} \\
\hline & \multicolumn{12}{|c|}{ Grain weight (mg) } \\
\hline & & $P$ & & $P$ & & $P$ & & $P$ & & $P$ & & $P$ \\
\hline B93 & $60 \cdot 0$ & $<0 \cdot 01$ & $62 \cdot 0$ & $<0 \cdot 01$ & -0.7 & NS & $36 \cdot 0$ & NS & $0 \cdot 0$ & NS & $14 \cdot 0$ & $<0.05$ \\
\hline CM105 & $18 \cdot 0$ & NS & $11 \cdot 0$ & NS & $6 \cdot 1$ & NS & $33 \cdot 0$ & NS & $0 \cdot 0$ & NS & $-1 \cdot 2$ & NS \\
\hline EA2024 & $-26 \cdot 0$ & NS & $-27 \cdot 0$ & NS & $-0 \cdot 4$ & NS & $-22 \cdot 0$ & NS & $0 \cdot 0$ & NS & $4 \cdot 9$ & NS \\
\hline EC13A & $-7 \cdot 9$ & NS & $-1 \cdot 8$ & NS & $-4 \cdot 7$ & NS & $-20 \cdot 0$ & NS & $0 \cdot 0$ & NS & $12 \cdot 0$ & NS \\
\hline EP29 & $7 \cdot 7$ & NS & $10 \cdot 0$ & NS & $-1 \cdot 7$ & NS & $0 \cdot 9$ & NS & $0 \cdot 0$ & NS & $8 \cdot 7$ & NS \\
\hline EP39 & $-51 \cdot 0$ & $<0.01$ & $-54 \cdot 0$ & $<0.01$ & $1 \cdot 3$ & NS & $-29 \cdot 0$ & NS & $0 \cdot 0$ & NS & $-2 \cdot 9$ & NS \\
\hline $\begin{array}{l}\text { Average } \\
\text { dominance }\end{array}$ & $82 \cdot 0$ & $<0.01$ & NS & NS & 81 & $<0.01$ & NS & NS & $93 \cdot 0$ & $<0 \cdot 01$ & NS & NS \\
\hline
\end{tabular}

* Model I average dominance was fixed and general additive effects were random.

$\uparrow$ Model II average dominance was fixed and general additive and dominance effects were random.

\$ Model III average dominance was fixed, and general additive, dominance and epistatic effects were random.

NS, not significant.

\section{Correlations}

Grain density showed a negative correlation with flotation NIRS estimates $(r=-0 \cdot 41, P<0 \cdot 01)$. Also, a significant correlation between FMT and flotation NIRS estimates $(r=0.56, P<0 \cdot 01)$ was detected. The positive significant correlation between grain weight and FMT $(r=0.33, P<0.01)$ indicates that higher the grain yield the more flour can be produced after milling for a given time. The strong positive correlation between grain weight and grain yield $(r=0 \cdot 68$, $P<0 \cdot 01)$ suggests that as the grain size increases the grain yield also rises. 


\section{DISCUSSION}

The environment had insignificant effects on damage index and was the most important factor for the FMT, which indicates that environmental conditions may determine the state of the grain for ease of milling. This implies that GD and density may not clearly differ among these genotypes.

The genetic model proposed was sufficient for explaining the genetic effects in the behaviour of genotypes. However, the model was not sufficient for explaining the whole genotype variation for FT and for grain weight, probably because the error term does not include the genotype $\times$ environment interaction effects. The genotype $\times$ environment interaction is known to affect the yield and other agronomic traits, although not so much for quality-related traits (Medici et al. 2004). Partitioning of the variation of the model into genetic effects showed that the magnitude of effects was diverse for the different traits.

Grain yield: Dominance effects were larger than additive and epistatic effects. These results are in agreement with the findings of previous workers (Hallauer \& Miranda 1988). However, the relative importance of additive and dominance effects strongly depends on the genotypes; for example, Badu-Apraku et al. (2004) and Medici et al. (2004) found the additive effects to be the most important for yield in a tropical synthetic population. Partitioning of the dominance source of variation into components revealed that the average dominance mean square was several times larger than that due to general dominance, whereas the specific dominance mean square was not significant. Several studies on heterosis among maize populations reported that the average heterosis was the main component of variation due to heterosis for grain yield (Ordás 1991; Moreno-González et al. 1997; Soengas et al. 2003). The average heterosis is even more important in the present study, because the parents of the diallel were inbreds.

The epistatic variation in the two environments was not significant, probably due to the large genotype $\times$ environment interaction. This corroborates the results of Darrah \& Hallauer (1972). Stuber \& Moll (1974) found that the importance of epistatic effects decreased with environmental $\times$ epistasis interactions. Moreno-Gonzalez \& Dudley (1981) also indicated that part of the epistatic variation could have been removed with the additive and dominance variation because of the non-orthogonality of the parameters in sequential analyses. The difficulties in detecting epistasis were observed by Lamkey \& Edwards (1999) indicating that an appropriated method for estimating epistasis with precision is still elusive (Hinze \& Lamkey 2003).

A positive average dominance effect was the most important genetic effect for grain yield. Positive significant additive and dominance effects were detected for inbred B93 and negative effects for inbred EP39. No significant epistatic effects for grain yield were detected when the two environments were considered, however, positive specific epistatic effects were found in seven out of 15 crosses in the Mabegondo environment. The genetic $\times$ environment interaction diminished the importance of epistatic effects. Wolf \& Hallauer (1997) found significant epistatic effects for some inbreds and specific crosses in grain yield, although they were generally much less important than the other genetic effects. Furthermore, Hinze \& Lamkey (2003) found that epistasis was rarely significant for grain yield.

Therefore, breeding for high yield should involve hybridization, as expected based on previous knowledge and reports from other papers, while the improvement of yield expected from the contribution of additive or epistatic effects would result in smaller gains.

FMT: Additive effects were the largest among all genetic effects for this trait. The variation due to dominance effects was not significant when genotypes were tested in the two environments because of the large genotype $\times$ environment interaction. However, specific dominance was detected, suggesting that some specific crosses could show dominance effects. The additive $\times$ additive epistatic variation was not significant for the FMT.

For FMT, additive effects for the Plata inbreds EA2024 and EP39 and for the soft endosperm inbreds B93 and EP29 suggest that the inbreds related to Plata germplasm and their derived crosses are appropriate for breeding for hard endosperm since these lines produce larger particles after milling. In contrast to yield, breeding for FMT would be more efficient if based on additive effects.

GD index: Genotypic variation for GD was not significant in the combined ANOVA. If the experimental error was used as denominator in $F$-tests instead of the genotype $\times$ environment interaction mean squares, the genotypic variation would be significant, thus the different responses of genotypes to environments might have masked the importance of genotype variation per se for this trait. Dominance mean square was significant. When the dominance source of variation was partitioned into components, the mean squares of average dominance related to average heterosis was very large suggesting a high significant difference between inbreds and hybrids for resistance to GD. Additive mean square was smaller than that due to dominance effects for these traits.

For GD, average dominance indicates that hybrids are less susceptible to post-harvest damage than inbreds. The inbred CM105 showed positive while EP29 had negative additive effects, and both B93 and CM105 had positive epistasis effects. Therefore, 
based on the genetic regulation of this trait, the expected gains from breeding would be very low.

Grain density: The variation due to genotypes was not significant, however, additive and dominance effects were significant, which indicates that these two types of effects are mainly governing the genetic behaviour of genotypes for grain density without significant influence of epistatic effects. Additive effects were larger than dominance effects. Small improvements in grain density could be expected in a breeding programme based on either additive or dominance effects.

Finally, for FT and grain weight, additive effects were larger than dominance effects. Grain density, FT and FMT are related to each other. As grain density increases, the ease of milling and the flotation index of grains decrease. Medici et al. (2004) also found that additive effects were more important than dominance effects for grain weight. These traits are directly related to grain size, for which Audilakshmi \& Aruna (2005) have found dominance and epistatic effects to be significant in sorghum. Monneveux et al. (2008) found a strong correlation between grain weight and yield, and Dorsey Redding et al. (1991) also found that the hardness was correlated with other quality factors like test weight (apparent density) and grain density. The higher the grain yield, the more flour produced after milling in a given time; as the grain size increases, the grain yield also rises. Therefore, flotation and grain weight can be improved through selection. Correlations among grain-quality traits and yield are neither consistent among genotypes nor across years (Badu-Apraku et al. 2004). Furthermore, correlations between yield and each quality trait changes among selection programmes, which implies the need for regularly checking the direct and correlated responses to selection (Monneveux et al. 2008).

Considering all traits together, the hard endosperm quality traits showed mainly an additive genetic variation. On the contrary, dominance effects related to heterosis explained most of the variability for grain yield and GD. In general, additive $\times$ additive epistatic variation was not significant; this fact could be attributed to (i) part of the variation might have been removed by additive and dominance effects when performing the sequential ANOVA, and (ii) the relative importance of epistasis $\times$ environment interaction. The average dominance was the most important component of the dominance variance as compared with general and specific dominance. Average dominance is related to a heterosis of hybrids over inbreds, producing an increment of grain yield, size, hardness, density and resistance to damage. Flotation index was the trait that best characterized the hard endosperm quality since variation among genotypes was relatively large and an NIRS equation showing a good prediction was developed $\left(R^{2}=0 \cdot 87\right)$.

Some inbreds displayed sufficient potential to be used in hard-grain maize breeding programmes. Inbreds EA2024 and EP39 related to Plata maize showed significant favourable additive effects for traits related to hard endosperm. In addition, inbred B93 showed the highest additive and dominance effects for grain yield and moderate negative effects for the FT index. Results suggest that improvement for traits related to hard endosperm quality should be easily reached by hybrid breeding programmes, since average dominance was the most important effect for grain yield and traits related to hard endosperm. Other authors have also shown that local germplasm contributing high grain density frequently have lower yield than the modern hybrids (Krieger et al. 1998; Singh et al. $2001 a, b$ ). These high-quality accessions would be valuable for contributing favourable alleles for improving grain quality for milling, but the improvement of yield should rely on elite inbreds. The combination of the Spanish inbreds evaluated here with some appropriate elite inbreds for improving yield would result in correlated gains for milling test and grain weight, but would also involve a reduction in grain density.

This research was supported by the European Commission and the Ministry of Science and Technology of Spain) (Project code 1FD1997-2352C02-01) and the INIA (Project code RF2007-00007$\mathrm{C} 05)$.

\section{REFERENCES}

Audilakshmi, S. \& Aruna, C. (2005). Genetic analysis of physical grain quality characters in sorghum. Journal of Agricultural Science, Cambridge 143, 267-273.

Badu-Apraku, B., Fakorede, M. A. B., Menkir, A., Kamara, A. Y. \& Adam, A. (2004). Effects of drought screening methodology on genetic variances and covariances in Pool 16 DT maize population. Journal of Agricultural Science, Cambridge 142, 445-452.

Chandrashekar, A. \& Mazhar, H. (1999). The biochemical basis and implications of grain strength in sorghum and maize. Journal of Cereal Science 30, 193-207.
Darrah, L. L. \& Hallauer, A. R. (1972). Genetic effects estimated from generation means in four diallel sets of maize inbreds. Crop Science 12, 615-621.

Dorsey-Redding, C., Hurburgh, C. R. Jr., Johnson, L. A. \& Fox, S. R. (1991). Relationships among maize quality factors. Cereal Chemistry 68, 602-605.

Eberhart, S. A. (1964). Least squares method for comparing progress among recurrent selection methods. Crop Science 4, 230-231.

Eberhart, S. A. \& Gardner, C. O. (1966). A general model for genetic effects. Biometrics 22, 864-881. 
EUROSTAT (2005). Agricultural statistics, Quarterly bulletin No. 5. Farm structure survey. http://epp.eurostat. ec.europa.eu/cache/ITY_OFFPUB/KS-NT-05-S01/EN/ KS-NT-05-S01-EN.PDF (verified 11 June 2008).

FAO (1992). Maize in Human Nutrition. Food and Nutrition Series No. 25. Rome: FAO.

FAST, R. B. (1990). Manufacturing technology of ready-toeat cereals. In Breakfast Cereals and How they are Made (Eds R. B. Fast \& E. F. Caldwell), pp. 15-42. St Paul, MN, USA: AACC Inc.

Hallauer, A. R. \& Miranda Filho, J. B. (1988). Quantitative Genetics in Maize Breeding, 2nd edn. Ames, IA, USA: Iowa State University Press.

Henry, R. J. \& Kettlewell, P. S. (1996). Cereal Grain Quality. London: Chapman \& Hall.

Hinze, L. L. \& Lamkey, K. R. (2003). Absence of epistasis for grain yield in elite maize hybrids. Crop Science $\mathbf{4 3}$, $46-56$.

Krieger, K. M., Pollak, L. M., Brumm, T. J. \& White, P. J. (1998). Effects of pollination method and growing location on starch thermal properties of corn hybrids. Cereal Chemistry 75, 656-659.

Lamkey, K. R. \& Edwards, J. W. (1999). The quantitative genetics of heterosis. In Proceedings of the International Symposium on The Genetics and Exploitation of Heterosis in Crops (Eds J. G. Coors \& S. Pandey), pp. 31-48. Madison, WI, USA: ASA, CSSA and SSSA.

Matz, S. A. (1991) The Chemistry and Technology of Cereals as Food and Feed, 2nd edn. New York: Van Nostrand Reinhold.

Medici, L. O., Pereira, M. B., Lea, P. J. \& Azevedo, R. A. (2004). Diallel analysis of maize lines with contrasting responses to applied nitrogen. Journal of Agricultural Science, Cambridge 142, 535-541.

Monneveux, P., Sanchez, C. \& Tiessen, A. (2008). Future progress in drought tolerance in maize needs new secondary traits and cross combinations. Journal of Agricultural Science, Cambridge 146, 287-300.
Moreno-GonzÁlez, J. \& Dudley, J. W. (1981). Epistasis in related and unrelated maize hybrids determined by three methods. Crop Science 21, 644-651.

Moreno-González, J., Ramos-Gourcy, F. \& Losada, E. (1997). Breeding potential of European flint and earlinessselected U.S. corn belt dent maize populations. Crop Science 37, 1475-1481.

Ordás, A. (1991). Heterosis in crosses between American and Spanish populations of maize. Crop Science 31, 931-935.

Robutti, J., Borrás, F., Ferrer, M., Percibaldi, M. \& Knutson, C. A. (2000). Evaluation of quality factors in Argentine maize races. Cereal Chemistry 77, 24-26.

SAS Institute Inc. (1999). SAS Stat User's Guide, version 8. Cary, NC, USA: SAS Institute. Inc.

Singh, S. K., Johnson, L. A., Pollak, L. M. \& Hurburgh, C. R. (2001a). Compositional, physical, and wet-milling properties of accessions used in Germplasm Enhancement of Maize project. Cereal Chemistry 78, 330-335.

Singh, S. K., Johnson, L. A., Pollak, L. M. \& Hurburgh, C. R. (2001 b). Heterosis in compositional, physical, and wet-milling properties of adapted $\times$ exotic corn crosses. Cereal Chemistry 78, 336-341

Soengas, P., Ordás, B., Malvar, R. A., Revilla, P. \& Ordás, A. (2003). Heterotic patterns among flint maize populations. Crop Science 43, 844-849.

Stuber, C. W. \& Moll, R. H. (1974). Epistasis in maize (Zea mays, L.): IV. Crosses among lines selected for superior inter-variety single cross performances. Crop Science 14, 314-317.

Watson, S. A. \& Ramstad, P. E. (1987). Corn: Chemistry and Technology. St. Paul, MN, USA: American Association of Cereal Chemists.

Wolf, D. P. \& Hallauer, A. H. (1997). Triple testcross analysis to detect epistasis in maize. Crop Science 37, 763-770.

Xu, Z. C. \& ZHU, J. (1999). An approach for predicting heterosis based on an additive, dominance and additive $\times$ additive model with environment interaction. Heredity 82, 510-517. 